\title{
“LOSER” AESTHETICS: Korean internet freaks and gender politics
}

\author{
Sunyoung Yang
}

Department of East Asian Studies, University of Arizona, Tucson, Arizona, USA

Email: sunyoungyang@email.arizona.edu

\section{ARTICLE HISTORY}

Received 4 August 2017 / Revised 17 July 2018 / Accepted 18 July 2018

\begin{abstract}
In the aftermath of the 1997 Asian Financial Crisis, a new Internet freak culture emerged in South Korea in response to the rapid development of the Internet as well as the country's neoliberal reforms. At this time, images of losers, freaks, and other "surplus" populations circulated online. This article examines the gender politics of "Internet freaks" through an analysis of one online fan forum, the Lee Joon Gi gallery of DCinside.com. Lee’s fan forum acquired a reputation through sexually charged posts from its female-user base in the late 2000s and is still active today. By appropriating attributes of online male culture and forms of communication, such as absurd statements, rudeness, and aggressive sexual expression, the users of this fan community created a carnivalesque space for themselves and subverted rigid Korean gender ideologies. Such parodies have transformed the fear of misogyny and sexism in the offline world into laughter online and become fertile ground for changes in gender politics in online spaces.
\end{abstract}

\section{KEYWORDS}

Internet culture; female fandom; sexuality; politics of aesthetics; carnivalesque; South Korea 


\section{Introduction}

While subversive Internet user communities based on humor and trolling have been popular worldwide, one such group in South Korea (hereafter Korea) has been rewriting the rules for how digital nonconformists can have a measurable impact on real world politics. Adopting the moniker “Internet freaks” (int'ónet p’yein) ${ }^{1}$, this loosely organized group of online protesters, critics, satirists, and trolls have been active on Korea's DCinside.com, a well-known, anonymous Internet user forum based on the image board system and composed of thousands of "galleries" or interest groups. DCinside became popular because of its posts delineating the poor and unpromising lives of Koreans through comical, and sometimes graphic, parodic images. Users of DCinside have created self-deprecating labels for themselves including "Internet freaks,” the “pathetic” (tchijili), “otaku” (ot’ak’u), “idiots” (pyŏngjin), and “surplus (human)” (ingyŏ). Because DCinside affords anonymity, it has developed an atmosphere in which "anything goes,” including explicit language, impoliteness, and sexually charged posts. By and large, DCinside galleries have been a male-dominated forum. However, one notable female-led gallery is centered around the actor Lee Joon Gi and called the Lee Joon Gi gallery (hereafter the Joon gallery or "Joon gall," the short-form name given to the gallery by its users, who are also called "Joon gallers”; I use Lee for Joon Gi Lee when I refer to him, or Joon Gi when my interviewees refer to him). Lee's own fandom exploded after the box-office, record-breaking success of the film, The King and the Clown (Wang ŭi namja: Kwŏn 2005). In this film, Lee stars as Konggil, a beautiful male jester who is a female impersonator in a troupe of entertainers, and therefore, experiences being an object of men's sexual desire. Through his performance as Konggil, Lee established his reputation as a talented actor with his androgynous appearance giving him the nickname kkonminam, meaning "good-looking 
man with feminine characteristics” (Shin 2013, 98). As Jeeyoung Shin points out, Lee’s feminine masculinity appealed a great deal to women "who counter traditional values by being active, aggressive, and independent” (2013, 99). Lee’s fandom is an ideal forum to examine the evolving dynamics as new roles for both men and women and their changing sexuality are observed. The Joon gallery has successfully grown into one of the most popular galleries since the late 2000s by employing the same tactics, culture, and style of the male-dominated fora. ${ }^{2}$ How has the Joon gallery created space for itself within the largely masculine culture of DCinside? What kind of gender politics have Joon gallers developed in this online space?

I first noticed the gallery through Nunhwa images. When I saw a series of images with the Nunhwa mask, I wondered, “What the heck are these?” But soon I found myself addicted to those images. I found the Joon gallery and eventually came to live on DCinside and the gallery day and night. I found that the Joon gallery was the perfect place for me to inhabit. I had mainly visited fan websites where I had to be polite and nice. It was fascinating that I could say anything, even curse.

Madeleine ${ }^{3}$ one of my interviewees, recalled the first time she ever saw a movie featuring Lee and entered the Joon gallery. Like Madeleine, most of my interviewees were similarly drawn to the Joon gallery because of the funny images attracting them to DCinside. I, too, found myself drawn to the Joon gallery by those images long before I started my research on DCinside. Called a “series of Nunhwa mask” (nunhwa t'al sirijŭ literally meaning “a series of Older Sister mask”), these images are intriguing. They always feature two characters: the image of Lee and one or more of Lee's fans, Joon 
gallers. These characters wear the same style of the traditional Korean mask Lee wore in The King and the Clown (Kwŏn 2005). Many scenes present situations in which Lee and the other characters are sexually involved with each other and with the other characters coaxing, trying to seduce, and successfully taking advantage of Lee's online depiction.

I was fascinated by the emergence of the Joon gallery because of the conflicting conditions that have shaped the gallery: Korea's long-standing gender inequality and women’s marginalization, lack of public space for women's voices in the “real/physical” world, and naturalized ideologies of ideal women. Ironically, female Internet users found space for themselves and weapons to fight back against those conditions in the male-dominant, sexist, and anonymous DCinside where anything, including women's subordination, goes. These female Internet users appropriate attributes of online male culture and forms of communication, such as absurd statements, rudeness, and aggressive sexual expression to empower and emancipate themselves from expected gender norms and conformity. The Joon gallery deserves scholarly attention since its culture and code of conduct have played a leading role in bringing about more recent and diverse gender politics into online spaces. With intensified neoliberalization over the decades, extreme right-wing users from Ilbe.com ${ }^{4}$ and radical feminists such as Megalians ${ }^{5}$ have grown in conjunction with Internet freak culture. Online misogyny and feminist counterattacks have grown together in user communities over the decades since their formations. Korea's much more visible feminist movement of Megalia started on DCinside in 2015 while retaliating against the misogyny of DCinside and its offspring, Ilbe and more broadly Korean society in general, both online and real (also referred to as “offline”). Jeong and Lee (2018) call the convergence of online and offline worlds and experiences "augmented" realities and 
politics (2). The realities and politics in online and offline worlds have been augmented over a long time as Korea’s active “Me too” movements can be traced to Myŏnsun Kim, a female writer and musician in the early twentieth century's colonial period and more recently campus feminist movements in the 1990s (Yi 2018). The origin of the Joon gallery in the male-dominant culture of DCinside delineates the historical minutiae of augmented realities and politics.

For this paper, I draw on my anthropological field research conducted in both the online and offline worlds in Korea from 2008 to 2009 and 2017, as well as my continued online research in the years since. ${ }^{6}$ In this study, I examine two manifestations of gender: the character "Nunhwa", created by Joon gallers and posts containing aggressive sexual expressions featuring Lee and the Nunhwa character together. I interpret the Nunhwa character as a collective identity that Joon gallers create for the purposes of expressing self-referential mockery. The Nunhwa character and Joon gallers are apathetic, particularly in terms of conventional beauty and femininity. While infused with sexuality, the fandom of the Joon gallery is in line with other examples of fandom and current popular culture in Korea. However, traditional representations of popular culture emphasize physical appearance, whereas Joon gallers depict themselves as grotesque, unpleasant, and "pathetic."

To uncover the political meaning underlying this Internet freak culture, I find Jacques Rancière’s theory of “the politics of aesthetics” useful. The culture of DCinside and the Joon gallery show how previously powerless-from conventional perspectives — groups are able to make their voices audible by bringing about "new modes of sense perception and novel forms of political subjectivity” (Rancière 2004, 9) through the use of new information and communication technologies. Rancière’s work offers valuable conceptual tools to consider the implications of posts produced by 
DCinside users. Even though Rancière’s work is instructive, it does not adequately explain the rationale behind Joon gallers' use of social outcast characters and the deliberately shoddy styles that constitute “loser aesthetics” popular on DCinside (Yang 2017) instead of some other form of self-expression. To address this limitation, Mikhail Bakhtin's notion of carnival can be applied in combination with Rancière's theories to shed light upon this phenomenon. In line with the notion of Internet freaks, the various characters posted in galleries, which are produced, circulated, and popular on DCinside are mockingly comic, absurd, and grotesque figures, shape DCinside into a space similar to that of "the feast of fools" and "the feast of the ass," which Bakhtin praises in his theory of the carnival $(1984,5)$. In Bakhtin's carnival, the laughing truth defeats power through curses and abusive words (Bakhtin 1984, 90-3). Much like Bakhtin’s carnival, I find the laughter in DCinside is also a rejection of fear and a rebellion against a mystifying power. In this carnivalesque space, Joon gallers question and challenge gender ideologies through their transgression of different gender norms based on hegemonic conventions of "masculinity” and “femininity” (Butler 1990) and position themselves as “genderqueer” (Stryker 2008) wearing the Nunhwa mask that represents their collective identity.

\section{The contempt of fandom and the emergence of the Lee Joon Gi gallery}

To understand the culture of the Joon gallery, it is important to situate the gallery within the broader contexts of Korean fandom. The culture of Korean fandom has distinctively and historically been female dominated, starting with the narrators of silent films and women's classical opera (yǒsŏng kukkŭk) to pop singers, basketball players, and danceoriented singing groups known as “idol groups” (HP. Kim 2012). Even though loyalty and commitment are usually highly valued, female fans have been widely denigrated 
and assigned contemptuous nicknames such as “troops for a big brother” (oppa pudae) or more recently, "girl following a big brother” (ppasuni) (Kimi and Pak 2001; MH. Yi 2013). These terms describe the activities of these fans, that is, heartily cheering for their idols. Nevertheless, female fans are also derided as blind followers of popular culture and even as social deviants (HP. Kim 2012). These fans have been ridiculed but not intimidated by the harsh criticism of public discourse. Instead, they have carried on with their fervent support for their idols and simultaneously have reappropriated the condescending labels to assert their fan identities (Y. Song 1995).

Female-dominated Korean fandom did not materialize overnight; these fandoms are a tangible result of gendered modernity in Korea. Feminist scholars have examined the different ways Korean women and men have been "doing” modernity in postwar Korea (Abelmann 2003; Kendall 2002). Even with recent neoliberal social reforms, modernity in Korea still adheres to distinct gender roles and gender discrimination continues. For example, female workers were the first targets of large-scale layoffs and the flexibilization of the labor force due to the Asian Financial Crisis (S. Cho 1998, 910). In neoliberal Korea, the resurgence of the middle-class family ideology of a male breadwinner and a female homemaker has restricted women’s space in the public domain (J. Song 2009, 52). Haejoang Cho (2002) discusses the ways in which Korean women have been active in the "domestic/private domain” such as in real estate speculation and private education as a means of upward mobility (172-173) while their husbands have built their careers in the public domain, which has excluded women for generations (168). As women's frustrated desires for careers in the public domain have brought about a female-dominated domestic/private domain in Korea, the formations of gendered space and gendered modernity in Korea afford female-dominated fandom the opportunity to create a new domain. This place is located in between the private domain 
(personal hobby) and the public domain (popular culture). In this domain of popular culture and media, Korean women have formed themselves into "publics" and “counterpublics” (Warner 2002). Despite encountering denigration and stigmatization, fandom enables female fans to create their own communities, cultural products, aesthetic values and practices, as they test, play with, and redefine conventional gender ideologies. As Henry Jenkins (2007) provocatively claims, "Fandom represents the experimental prototype, the testing ground for the way media and culture industries are going to operate in the future” (361). DCinside as well as the Joon gallery are situated within the interplay among popular culture, fandom, and new technologies.

While the pervasive patriarchal ideology emphasizing women’s beauty is seen as repressive, this old ideology has been successfully restyled by a consumer culture promoting sexuality as the heart of self-fulfillment and has become a new ideology as women seek to cultivate attractive bodies (H. Cho 2002; Lee 2000). With the message that self-fulfillment can be achieved through sexuality, many female fans have started to embody the image of the sexy girl, which is a relatively recent gendered subjectivity brought about by a rising consumer culture. The Joon gallery appeared against a backdrop of a growing interest in popular culture, fandom, and sexuality.

While many online fan communities arose for Lee, the one on DCinside is notably different. The carnivalesque culture of DCinside has strongly influenced the style of the Joon gallery while the sexual nuances and self-deprecating posts are a unique part of the gallery. Joon gallers, who strongly assert themselves as sexual subjects, are deliberately anti-aspirational in terms of wanting or trying to become sexy and beautiful women. Rather, they style themselves according to their own unique aesthetics, critiquing and flouting the norms of feminine beauty popularized by the ad power of consumer culture. Through the activities of Joon gallers, this resistance to 
commercialized feminine beauty demonstrates the ways in which new gender norms are constituted via contestation and negotiation. The aggressiveness of Lee's fandom on DCinside actually performs double duty, critiquing both the long-standing rigid gender ideologies, as well as the neoliberal collusion to advocate these gender ideologies.

\section{Nunhwa and her mask: characterizing Joon gallers and gender}

As previously mentioned, DCinside users are known to develop characters that embody the DCinside ethos: self-parody in deliberately shoddy styles called loser aesthetics (Yang 2017). The creation and circulation of these characters allow users to engage in forms of self-mockery and create a space resembling medieval "carnivals” inflected by "the folk culture of humor", a theme that has been deliberated on by Bakhtin (1984). In a similar vein, the label Internet freak disparages those who use new technologies every day all day but for "trivial” reasons, which are different from those of innovative young entrepreneurs, the elite of the country. Other labels popular on DCinside also ridicule more specific subgroups such as otaku or different aspects of Internet users like the pathetic and surplus (humans) who are considered "losers” (Yang 2017). Joon gallers became famous for the creation of their own unique character Nunhwa and related posts, which affirmed Joon gallers' commitment to loser aesthetics although they were women as well as fans of a celebrity situated in an even lower stratum compared to male DCinside users, self-proclaimed social losers. ${ }^{7}$ As the self-mocking humor of Internet freaks provides powerful critiques of the social structures that transform the majority of its population into losers with only a small number of winners, Joon gallers use the same politics of loser aesthetics not only to become a part of the Internet freaks and DCinside but also to challenge the male-dominant cultures of DCinside and beyond. Joon gallers' loser aesthetics create double-layered politics reflecting the social 
structure that produces winners and losers, as well as the gendered social structure positioning women in an even lower stratum than male losers. Therefore, the politics of their loser aesthetics gestures to the process of emancipation and equality composed of practices to presume and verify that everyone is equal (Rancière 1992, 58-59).

Joon gallers' gender politics starts with their self-selected label, Nunhwa. This term intentionally plays upon the Korean kin term for a male’s older sister. Here Nunhwa is used as a fictive trope for sexual relations between an older woman and a younger man. By casting themselves as older and more experienced, Joon gallers dominate a younger man and subvert the long-standing power relationship between a younger woman and older man. This relationship authorizes Joon gallers to express their sexual desires through a known cultural idiom of kin terms as the traditional order of male dominance has done for men. The Nunhwa character is drawn wearing the mask that Lee wore in The King and the Clown. Familiar to Korean audiences, this mask is used in traditional theater and is common in a popular folk dance genre called t'alch'um. Wearing this mask, Lee satirizes gender hierarchies and the pretentiousness of the male ruling-class explicitly and loudly. Online, Joon gallers, too, strive to mimic this act of subversion. In their case however, they are not satirizing men's corruptive sexual desires; instead, they are asserting themselves as active, aggressive, and independent sexual subjects, not objects, of desire. Traditionally, the mask was used to satirize gender discrimination while still acknowledging its hegemony, but in the case of Joon gallers, they exercise their agency by playing with gendered and sexualized norms beyond simple satire and reappropriate it for self-expression.

For example, Figure 1, representing both tribute and self-mockery, is an example of the satirical image and voice of Nunhwa that appeared throughout a series of montage images edited and uploaded by users of the Joon gallery. Figure 1 includes 
Kkŭbyŏlsam (online username meaning three stars), three other popular Joon gallers, and their fanatic followers. Most notably, Kkŭbyŏlsam and her fans are all wearing Nunhwa masks or horse masks. These four Nunhwa are posing as famous rock stars, and although masks conceal their identities, these Nunhwa make themselves distinguishable with their rubber boots, jumpers or cardigans, and floral-print pants known as momppe. These culturally locatable clothing items intensify this form of selfparody, signifying the contemptuously viewed wife and mother.

Momppe pants are cheap, unsophisticated articles of clothing marked by loud prints and outdated designs. They are a recognizable form of clothing worn by Korean women in the countryside and worn daily in the home. Their gaudy designs are an instantly identifiable emblem of a social type in Korea: the ajumma, a term literally meaning “married woman.” The term ajumma carries certain negative images connected to married women, who are usually mothers and therefore not considered feminine, young, or attractive anymore (Ǒ. Kim 1998, 306-309). Beneath the benignly negative connotations of ajumma exists a cruel reality: married women are expected to sacrifice themselves continually as mothers and wives. The figure of the ajumma in momppe contrasts with the feminine neoliberal image of the "missi tribe” (missijok)—feminine housewives who take good care of themselves while remaining sexually attractive. For many married women in Korea, striving to look like those of the missi tribe can be a form of distancing themselves from labor and day-to-day drudgery. The contrast between the ajumma and missi tribe, the two most popular representations of married women, 


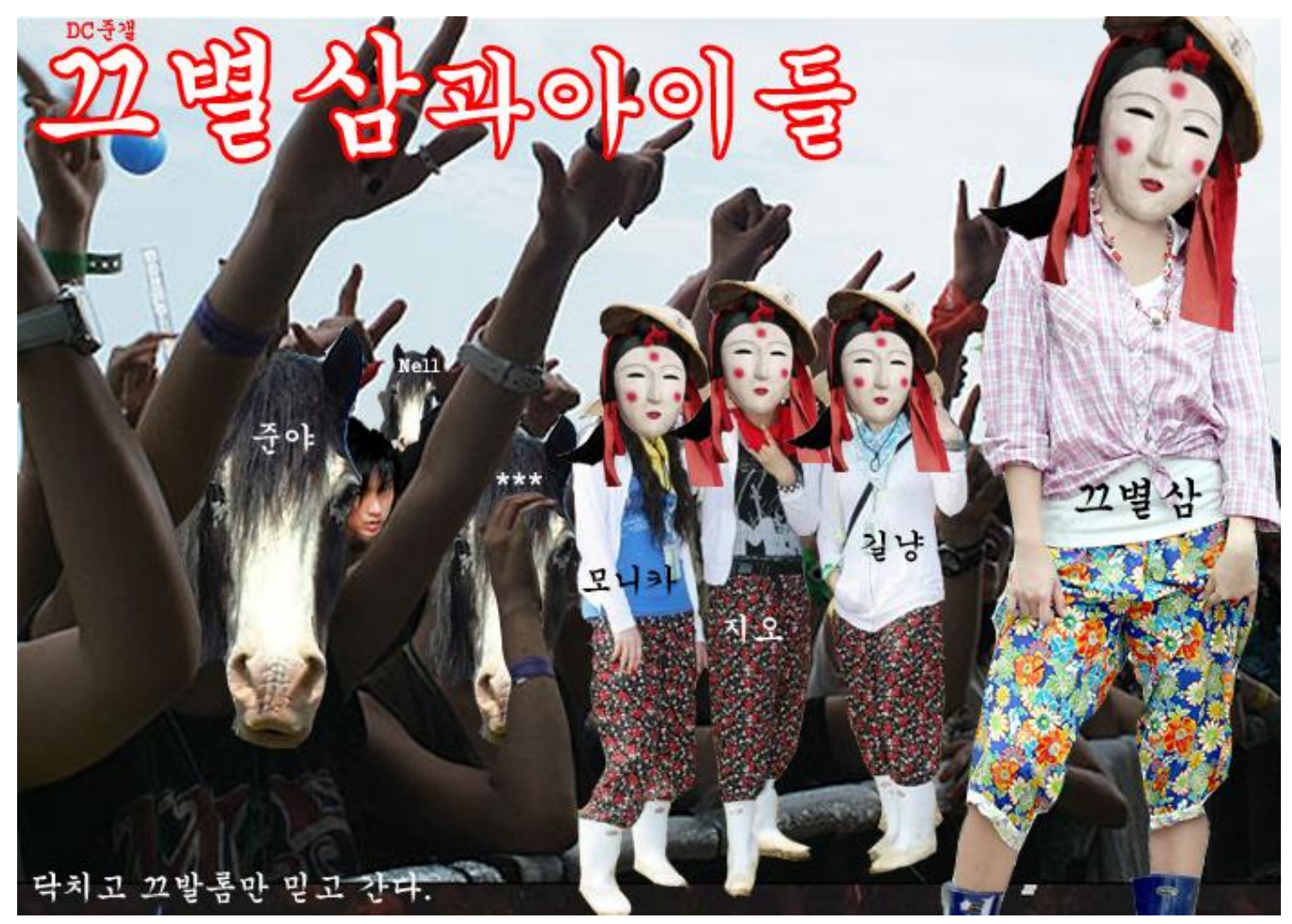

Figure 1. Kkŭbyŏlsam and kids: "We shut up and keep going following Kkŭbyŏlsam." Source: DC Joon gallery Mini Homepage on Cyworld.com. / I am using an image in the public domain.

demonstrates the conflicting patriarchal expectations for women. This package of old and new expectations demands that women continue to carry the burden of reproductive domestic labor in the private sector to support men in the public sector. In addition, a new gender subjectivity seeking self-fulfillment through sexuality driven by consumer culture emerged. Although undesirableness can be a stigma, it also emancipates women from the troublesome gender expectations and the practices of high-culture women.

Despite being viewed somewhat negatively, ajumma enjoy a certain freedom in society because they exist beyond the confines of sexualized power since they do not measure up to conventional notions of femininity. Nunhwa who appear wearing momppe consciously bring these connections into play with the mask. They draw on desexualized gender politics in order to challenge sexualized gender normativity. Using 
this stigmatized ajumma style creates a space of freedom-including freedom in their sexual conduct and discourse.

Additionally, Joon gallers also constitute a queer public because they are ambiguous in terms of gender. It can be understood that they take up the position of a queer subjectivity. As queer, the Nunhwa become defiant characters that disrupt gender norms, controversially performing selected aspects from different genders. The lines between femininity and masculinity blur because Nunhwa deploy and play with both femininity and masculinity. The practices of Nunhwa on the Joon gallery run parallel to Judith Butler's concept of gender parody. Butler (1990) argues that there is a subversive laughter that can be brought about by the pastiche-effect of parodic practices, which can "have the effect of proliferating gender configurations, destabilizing substantive identity, and depriving the naturalizing narratives of compulsory heterosexuality of their central protagonist: ‘man’ and ‘woman’” (146). Feminist scholars point out that Butler’s notion of performative identity may result in promoting bourgeois humanist individuality (Hennessy 2000; McElhinny 2003). Rosemary Hennessy (2000) contends that in Butler's arguments, the "postmodern subject is severed from the collective historical processes and struggles through which identities are produced and circulate” (121). Bonnie McElhinny (2003) also problematizes Butler’s concepts, as they remain “abstract rather than historically or socially precise” (32). McElhinny continues questioning the "limited range of activities, including play activities, movies, masquerades” in which gender can be so malleable. She argues that focusing only on this kind of situation "diverts focus from continuing patterns of exclusion, subordination, normalization, and discrimination” (31). By historicizing the emergence of the Joon gallery and its fandom and focusing on the collectivity found in the practices of Joon gallers, I believe there is value in the concept of gender performativity for 
assessing political engagement in gender ideology as well as exploring the individuality of the Joon gallery discourse. While the subversive bodily acts of Joon gallers do not explicitly reveal material inequities, they imply discontent with gender ideologies, which Hennessy also points out offers individuals an imaginary relationship to the material inequities they experience $(2000,19)$. Performative identities play a role in refracting such imaginary relationships and preventing individuals from accepting them as natural and seamless, which eventually contributes to the clarification of historical processes. The gender performativity of the Nunhwa enables Joon gallers to reflect on gender norms, including those that subjectify people into "men” and “women.”

Similarly, in their article “Taking a Bite out of Buffy: Carnivalesque Play and Resistance in Fan Fiction,” Amanda L. Hodge and Laurel P. Richmond (2011) examine fandom in relation to gender and sexuality with Bakhtin's carnival, Foucault's power relations, and Butler’s performativity. They analyze how fan fiction opens up a carnivalesque space online where fans navigate societal notions of gender in their own selective constructions of subjectivity by understanding gender, class, and social roles as fluid. Hodge and Richmond elaborate the way in which fans gain and wield power, how they "use and manipulate words, images, and technology to create bodies and selves through writing.” Buffy fandom based on a fan fiction community and Lee’s fandom on DCinside illustrate how certain fan cultures share commonalities regardless of regional and cultural backgrounds. As Hodges and Richmond (2011) point out, "to engage in carnival is not to set up any sort of binary but to interrogate and blur those that already exist. This ability to play, the desire to seek out or create tiny spaces for questioning and resistance, keeps discourses — and people—vital and fluid, always already in motion.” In the case of Nunhwa and the Joon gallery, it is particularly interesting to see the fans themselves appear on the stage as main characters through 
their fan products. According to my interviewees, the character Nunhwa is a key source of fun and freedom. While the actor Lee is the centerpiece of the gallery, he plays a role in supporting something more significant: female-dominant fandom taking a leading role.

\section{Playing with sexuality}

Using the mask for anonymity, Joon gallers indulge in sexual fantasies with the actor Lee in the voice and image of the Nunhwa character. Nunhwa is projected as confident in her sexuality, not intimidated or ashamed of openly expressing her sexual desire. Indeed, these depictions of sexual desire can even take the form of molestation or rape. Figure 2 portrays scenes of violent rape by female users. However, it should be noted these images are considered funny or dark humor by many Joon gallers.

In this figure, a group of “older sisters” threatens to rape the actor. One Nunhwa has pushed Lee with his back up against a wall, whispering, “Joon Gi, it’s me, your older sister. .. . I won't hurt you. Let's go to a tunnel. ... .” The other three Nunhwa watch with a clear expectation saying, "Next is our turn. ...” Lee, who looks younger than his actual age, more like a teenage boy, is crying, saying to himself, "Don’t look back. It is just a nightmare. Sob, sob. ...” What is provocative here is the open expression of female sexual desire united with the depiction of male submission.

Lee looks vulnerable and unable to stop the impending violence, especially since he is depicted as much younger and smaller than reality. Lee as the victim and the Nunhwa as the perpetrators run counter to traditional gender roles. However, the Nunhwa and Lee are still identified as ambiguously male and female, respectively. The Nunhwa and Lee, seen in Figure 2, fall under “genderqueer," according to Susan Stryker (2008) who defines genderqueer as variants of gender that include feminine 
men, masculine women, neutral gender, and transgender (20-21). Moreover, the popularity of female

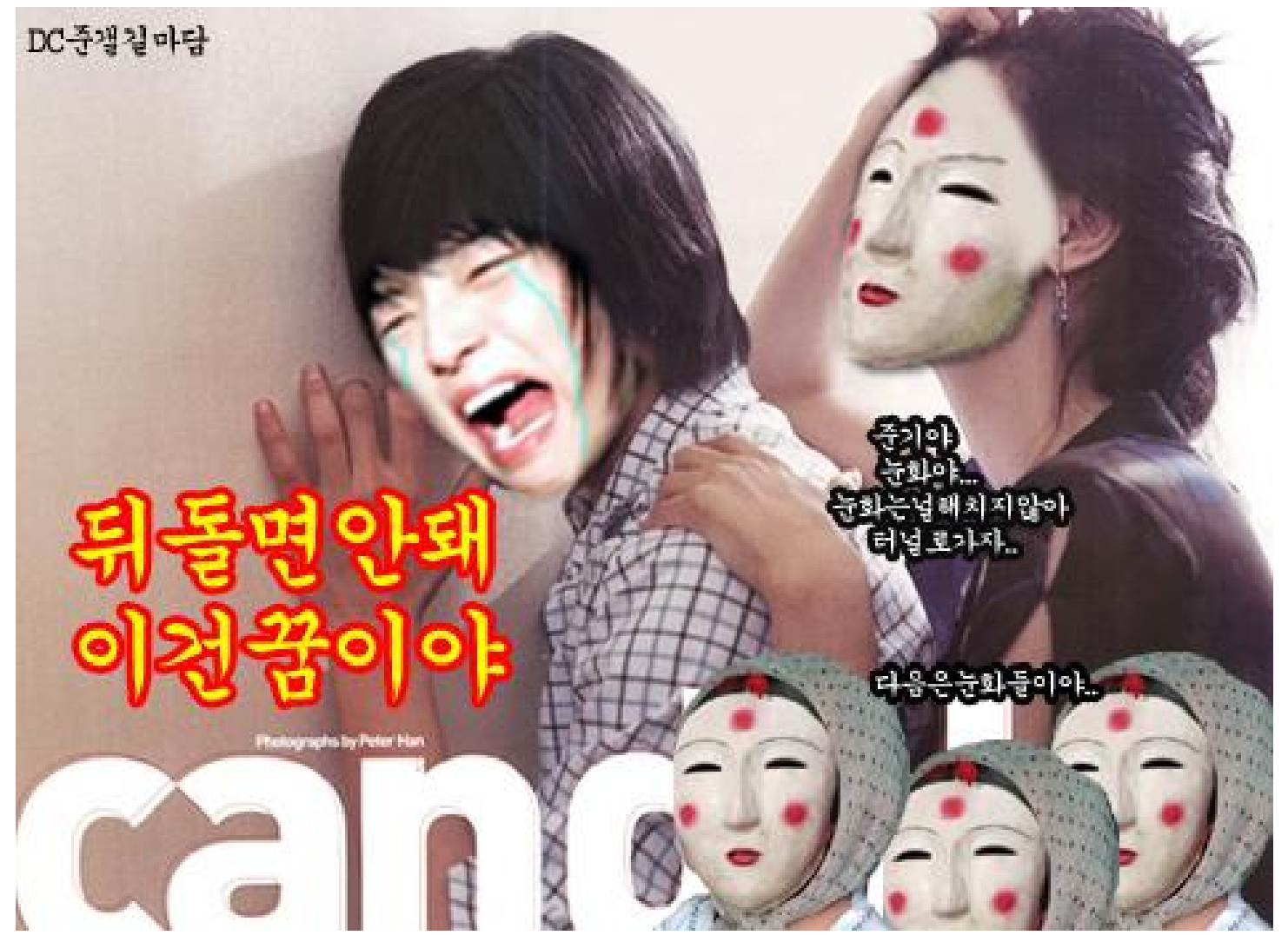

Figure 2. Don’t look back. It is just a nightmare. Source: Image made by DC chun'gi kael madam from DC Joon gallery Mini Homepage on Cyworld.com. / I am using an image in the public domain.

transvestitism in popular culture testifies to genderqueer's role in Korean gender politics. As Ji Hye Kim (2014) argues in her discussions of the heterosexual love of masculine women in Korean soap operas, these women reveal the performative nature of gender and how their heterosexual relationships undermine and transform the typical romance narrative $(10,40)$. As genderqueer, Lee and Nunhwa reveal the performative nature of gender like the masculine women in Kim's study while also rewriting the standard narrative of gender violence. Characters whose genders are not clear and violent situations that are comically exaggerated enable the gravity of rape to be read as 
a critique and mockery of conventional gender ideology in which men are active subjects of sexual aggression and women are passive objects of men's desire.

Online users find expressions of Nunhwa's sexual desire and Lee’s fear humorous because the situations and the characters in the posts are deliberately ambiguous and confusing. Comedy notwithstanding, women in Korea face the threat of violence as similar events play out in their real lives. In this sense, the Nunhwa image is dark, and the element of threat persists in the sexually charged posts, because if it did not, the images would not function as social satire, which by definition is a cutting form of humor. The imagery in Figure 2 is poignant because it reminds viewers of the violence women face in their everyday lives. The gender role reversal denaturalizes the violence, with some risk of perpetrating it, in a way that calls into question both the banal, everyday instances of violence experienced by women, and the uneven social relations that allow this routine violence to occur.

What does it mean to parodize such serious issues? The position embodied by the Nunhwa character does not translate into a position of power and authority in the real world. Like those who participate in Bakhtin's carnival of fools, these users align themselves with other Internet freaks. By twisting and exaggerating the roles of victim and predator, Joon gallers cast sexual violence and gender inequality in a new light and laugh them off. This act is accomplished through a peculiar assemblage of symbols easily recognizable to the Korean public: the traditional mask satirizing young women, ajumma garb, and the linguistic aggressiveness of men. They situate this humor within highly recognizable but taboo scenes of sexual violence. While there is a risk of reinforcing a conventional sentiment of violent pleasure through rape, the role reversal and the change of agency offers space to read familiar violence in different terms. Bypassing the severity brings about a cathartic release that overcomes fear and offers 
some solace for those trapped in a male-dominant culture. The Internet freak community gains political power through confronting and subverting the fear. DCinside users create a collage of signs and styles through a collaboration that inspires others to comment on and re-upload posts. Communicating or miscommunicating those signs and styles inspires new posts and laughter, which enable users to exist as a living entity of collective bodies like so many other online archives that are updated in real time.

\section{Ironic Laughter Between Online and Offline Worlds}

It is duly noted how difficult it is to determine how online practices play out offline. Even though I follow the way in which Joon gallers differentiate "online” space from the "offline” world, these metaphors lose meaning considering the ubiquitousness of network connectivity in everyday life. Rather, these metaphors indicate the way in which Internet users separate and manage different social groups and belongings. Online space offers more flexibility and anonymity in terms of donning different personas while influencing or being influenced by the offline world. While they industriously construct the collective identity of Nunhwa, many Joon gallers masquerade offline by playing a character, a "normal” person (ilbanin). This role is an example of a phenomenon called il-k'o which most of my interviewees said they practice in their real life. Il-k’o is an abbreviation for ilbanin k'osp'üre, and the term k'osp'üre (cosplay) is short for the Japanese k'ostyum p'ŭllei (costume play), which is costume role-play associated with subcultures such as comic books, manga, animation, video gaming, and TV shows. Thus, il-k'o is a kind of role reversal, indicating that participants become characters deemed normal in the real world while they consider their other identities such as a Joon galler or Nunhwa in an online space to be their genuine personhood. As the phenomenon of il-k’o demonstrates, Joon gallers seem to 
either hesitate or strategically choose not to actively challenge social expectations of gender norms in their offline lives. The Joon gallers' online experience, however, helps them to confront and negotiate gender ideologies in their everyday life.

I was witness to this practice by one Joon galler named No-rain (pseudonym of her online username) one weekend in mid-2009 when I went to her peach orchard to help her and her mother during their busy farming season. No-rain pursued multiple degrees and certificates after she finished a bachelor's in stage craft. As soon as she graduated, she enrolled in a computer-aided design certificate program but did not finish. Then she enrolled in and completed an art-therapy certificate program, only to realize that art therapy was not a good fit for her. While working as a teacher in a private fine arts institute for children, No-rain attended Korea National Open University, obtaining a bachelor's in education, and then started, but quit, a double major in English language and literature, and almost finished a degree in early childhood education.

Since her village practiced the rural tradition of labor exchange, I met many people who came to help while I worked. Everyone knew No-rain since she was born and raised in the village. After finishing a full day's work, we went to have dinner with No-rain’s neighbors, a middle-aged couple. Since No-rain’s mother was busy, she asked the couple to take us to a nearby restaurant because I was their guest. The meal, however, turned into an opportunity for the husband to berate No-rain's part-time job and appearance.

Our precious No-rain, do you want a second helping? I don’t think you can be full after that small amount of food... 
Hey you (towards me), are you not going to finish that? Why don't you give Norain your leftovers? She can easily finish it and actually needs it!... Why didn't you go to the reunion at your elementary school today? Didn't you want to meet your friends with successful careers? You should go and learn from them, sweetie...

I was shocked and speechless at the man's offensive remarks while No-rain deflected her neighbor’s comments abruptly saying, “Ah, please stop” (a chom kŭman haseyo), instead of submissively listening to him, which would be the traditional Korean response to respect elders. After dinner, No-rain said,

Yes, he is really annoying. But I can’t cause trouble by talking back to him too much since it is a small village where everyone knows everyone. I can’t ruin my mom’s social relations. After all, he doesn’t matter to me. He’s just a jerk.

No-rain's interaction indicates how the offline world presents more challenges where people must consider not only themselves but also their family members. Il-k’o or this less flagrant resistance toward gender roles can be interpreted as the Joon gallers’ attempt to find balance between online and offline groups, different customs and personas rather than a limitation of “online” politics because there is no pure "online” or “offline” world. Although No-rain was physically limited and isolated in her hometown where older men easily insulted her, she had her own community for support and knew those men were out of line. As conceptualized by Rancière (2004), the Internet community changes the "distribution of sensible" by transcending the limit of time and 
space, merging the online and offline worlds, and combining individual lives and experiences together into collective ones.

While traditional views of women persist in Korean society, transgressive images such as Nunhwa demystify norms of femininity and masculinity. The Nunhwa, with their mask, their costumes, and their fraught relationship with Lee, function as the "preliminary acting out of the dilemmas of femininity" in the "hyperbolic" mode that the "masquerade and carnival do in Rabelais and his world," according to Mary Russo (1995). Of the senile pregnant old hags depicted in Kerch terracotta, Russo asks, "Why are these old hags laughing?” $(1995,73)$. Here, this feminist point of view challenges Bakhtin's explanation of a coexistence of death and birth/new life $(1984,25)$. In hopes of possibly seeing a female grotesque in the context of feminist critiques and movements, Russo asks,

For now, right now, as I acknowledge the work of feminists in reconstituting knowledge, I imagine us going forward, growing old (I hope), or being grotesque in other ways. I see us viewed by ourselves and others, in our bodies and in our work, in ways that are continuously shifting the terms of viewing, so that looking at us, there will be a new question, the question that never occurred to Bakhtin in front of the Kerch terracotta figurines—-Why are these old hags laughing? (Russo 1995, 73).

The old hags might be laughing because they have also found the path to overcome the fear of misogyny and sexism, feeling power in laughter. The Nunhwa also laugh under their satirical mask while they enjoy transvestism and transgressions that are not acceptable in Korean society. They are laughing not because they have conquered the 
male-dominant culture of DCinside and the offline world but because they find themselves unable to surrender to or be afraid of it.

\section{Conclusion}

This paper focused on the interplay among fandom, online space, sexuality, and gendered modernity. The paper examined the ways in which Joon Gi Lee’s fans played with and challenged gender ideologies through sexuality and role reversal in an online space. The construction of an online personae has become a new gender, and by creating the ambiguous character Nunhwa, Joon gallers explore and confront traditional notions of gender rather than timidly accepting them. Through the content they produce, Joon gallers interrogate hegemonic gender norms in a playful way, and through DCinside, they open up a space where the conventional social order, including gender norms, is contested and reconfigured.

DCinside and loser aesthetics are deeply related to the social changes that neoliberalization has brought about. The sentiment of being a loser reflects the incredible societal pressure on subjects to be accountable and self-sufficient while being competitive and successful. Their self-reflexive and self-mocking insights have culminated in the politics of loser aesthetics, turning DCinside into a carnivalesque space where social losers wield power and challenge the principles of the dominant social order including class and gender. As the process of neoliberalization has unfurled, Korean women continue to be subjected to discrimination as they had been throughout the history of gendered modernity of Korea. Through hard-won debates and struggles, female Internet freaks have expressed their voices clearly and aggressively through the politics of loser aesthetics against a male-dominant culture that operates in the offline as well as online world. 
${ }^{1}$ DCinside posts and interviews used in this paper were originally in Korean. I translated these data and the labels indicating Internet users including DCinside users into English.

${ }^{2}$ When the Joon gallery was opened on January 25, 2006, around 3000 posts were uploaded within a couple of days with the number of views from 300 to 2000. Since then, the Joon gallery has been active due to Lee’s successful TV programs especially during its early years in the late 2000s. While a round 600 posts were uploaded per day until 2007, 120 posts per day is the usual pace nowadays when Lee's TV shows are on air. The number of views for each post is still high from 100 to 600 .

${ }^{3}$ All names are pseudonyms of my interviewees’ online usernames.

${ }^{4}$ Derived from DCinside in 2010, this website has progressively gained popularity with right-wing Korean Internet users and has run parallel with the victories of conservative parties in national elections in the past decade (Hak-chun Kim 2014).

${ }^{5}$ Megalians emerged from the MERS (Middle East Respiratory Syndrome, merŭsŭ) gallery on DCinside in 2015. Users of the MERS gallery started slandering Korean men in general focusing on their physical appearance, wealth, cultural attainments, and gender sensitivity by employing the same style and content male Internet users, especially from DCinside and Ilbe, have used to degrade women. This reverse sexism and hate speech soon gained the name "mirroring” (mirŏring) as a tactic of gender politics based on parody (Jeong and Lee 2018; Min-sŏk Yu 2016; Po-ra Yun 2017). ${ }^{6}$ In total, I interviewed 23 people active on DCinside, including eight from the Joon gallery, through online chats and in-person meetings. Most interviewees and acquaintances from the Joon gallery were single women, college students or graduates, in their twenties but there were also different age groups, males, married people, and 
non-Korean users as well. In this paper, I focus on two interviewees, both women in their twenties. DCinside, including the Joon gallery, does not require a membership subscription. Consequently, posts on DCinside are open to the public. I consider posts from the Joon gallery as published material and follow the rule of citation used among DCinside users as I use them here.

${ }^{7}$ As much as it attracted attention on DCinside and beyond, the Joon gallery endured many attacks called “robbing a gallery” (kael t’ŏgi) from other male-dominated galleries in its early heyday. Since Joon gallers were tough, they successfully protected their gallery and counterattacked other male-dominated galleries. Robbing other galleries has been considered a form of play on DCinside. Refer to Kilho Yi's book on DCinside that examines the culture of DCinside based on anthropological theories of tribal wars and gift-giving (Kilho Yi 2012). 


\section{Disclosure statement}

No potential conflict of interest was reported by the author.

\section{Notes on contributor}

Sunyoung Yang is a cultural anthropologist and assistant professor in the Department of East Asian Studies, University of Arizona. Her current research focuses on writing a real-time history of digital society, starting with the Internet and expanding to newly emerging digital technologies. Email:sunyoungyang@email.arizona.edu

\section{References}

Abelmann, Nancy. 2003. The Melodrama of Mobility: Women, Talk, and Class in Contemporary South Korea. Honolulu: University of Hawai‘i Press.

Bakhtin, Mikhail. 1984. Rabelais and His World. Translated by Hélène Iswolsky. Bloomington, Indiana: Indiana University Press.

Butler, Judith. 1990. Gender Trouble: Feminism and the Subversion of Identity. New York: Routledge.

Cho, Haejoang. 2002. "Living with Conflicting Subjectivities: Mother, Motherly Wife, and Sexy Woman in the Transition from Colonial-Modern to Postmodern Korea.” In Under Construction: The Gendering of Modernity, Class, and Consumption in the Republic of Korea, edited by Laurel Kendall, 165-195. Honolulu: University of Hawai'i Press,

Cho, Soon-Kyoung. 1998. "Kyŏngje wigi wa yŏsŏng koyong chŏngch'I” [Economic crisis, women's work and employment politics]. Han'guk Yŏsŏnghak [Journal of Korean Women's Studies] 14 (2): 5-33.

Hennessy, Rosemary. 2000. Profit and Pleasure: Sexual Identities in Late Capitalism. New York; London: Routledge.

Hodges, Amanda L. and Laurel P. Richmond. 2011. "Taking a Bite out of Buffy: Carnivalesque Play and Resistance in Fan Fiction.” Transformative Works and Cultures 7. http://journal.transformativeworks.org/index.php/twc/article/view/265/231, accessed on July 1, 2018. 
Jenkins, Henry. 2007. “Afterword: Future of Fandom.” In Fandom: Identities and Communities in a Mediated World. Jonathan Gray, Cornel Sandvoss, and C. Lee Harrington, eds. Pp. 357-364. New York: New York University Press.

Jeong, Euisol, and Jieun Lee. 2018. We Take the Red Pill, We Confront the DickTrix: Online Feminist Activism and the Augmentation of Gendered Realities in South Korea. Feminist Media Studies, DOI: 10.1080/14680777.2018.1447354.

Kendall, Laurel. 2002. “Introduction.” In Under Construction: The Gendering of Modernity, Class, and Consumption in the Republic of Korea, edited by Laurel Kendall, 1-24. Honolulu: University of Hawai'i Press.

Kim, Hak-chun. 2014. 'Int'ŏt kŏmyunit'i 'Ilbe chŏjangso' esŏ nat'ana nŭn hyŏmo wa yŏlgwang ŭi kamjŏng tonghak" [Dynamics of Cyber Hate and Effervescence; Focusing on the Korean Internet Community 'Ilbe-Joejangso']. Master's Thesis., Seoul National University.

Kim, Hwan-p'yo. 2012. "P'aendŏm ŭi yŏksa (1)" [The history of fandom (1)] Inmul kwa sasang [Figure and Thought] 176: 161-185. http://www.dbpia.co.kr/Journal/ArticleDetail/NODE02025495, accessed on July 1, 2018.

Kim, Ji Hye. 2014 “T'T'ibi tŭrama e nat'anan yŏnae kakpon ŭi pyŏnghyŏng kwa chendŏ/seksyuŏllit'i chaehyŏn e taehan yŏn'gu" [A Study of the Revised Romance Script and Representations of Gender/Sexuality in The First Coffee Prince(2007) and Wild Romance(2012)]. Chendŏ wa munhwa [Gender and Culture] 7(2): 7-40.

Kim, Ŏjun. 1998. Ddanji Ilbo 2 [Ddanji Daily News, Vol. 2]. Seoul: Chajak Namu.

Kimi, Sŭng-yŏn and Chŏng-ae Pak. 2001. "Ppasuni, oppa pudae, munhwa undongga?: Sŏ Tae Ji p'aendŏm iyagi” [Ppasuni, Troops for Big Brother, and Cultural Activists?: The Story of Seo Tae Ji Fandom], Yŏsŏng kwa sahoe [Women \& Society] 13: 158-175.

http://www.dbpia.co.kr/Journal/ArticleDetail/NODE01082896, accessed on July 1, 2018.

Lee, Young-ja. 2000. “Consumer Culture and Gender Identity in South Korea.” The Asian Journal of Women's Studies 6 (4): 11-38. https://www.dbpia.co.kr/Journal/ArticleDetail/NODE02113061, accessed on July 1, 2018.

McElhinny, Bonnie. 2003. "Theorizing Gender in Sociolinguistics and Linguistic Anthropology.” In The Language and Gender Handbook, edited by Janet Holmes and Miriam Meyerhoff, 21-42. Oxford: Basil Blackwell.

Rancière, Jacques.

1992. "Politics, Identification, and Subjectivization.” Identity in Question 61: 58-64. https://www.jstor.org/stable/778785?seq=1\#page scan tab contents, accessed on July 1, 2018. 
2004. The Politics of Aesthetics: The Distribution of the Sensible, translated by Gabriel Rockhill. London: Continuum.

Russo, Mary. 1995. Female Grotesques: Risk, Excess, and Modernity. New York; London: Routledge.

Shin, Jeeyoung. 2013. "Male Homosexuality in The King and the Clown: Hybrid Construction and Contested Meanings.” The Journal of Korean Studies 18: 89114. https://muse.jhu.edu/article/511083/pdf, accessed on July 1, 2018.

Song, Jesook. 2009. South Koreans in the Debt Crisis: The Creation of a Neoliberal Welfare Society. Durham: Duke University Press.

Song, Yŏng-ok. 1995. “Sin sedae sŭt'ŭresŭ haesoch'aek, ch'ŏngsonyŏn 5\% na to obba pudae, 2 ch'ŏn 2 paek myŏng chosa" [New Generation's Solution of Stress Reduction, 5\% of Youth Say Is Being a Member of "Troops For Big Brother," Based on Survey of 2,200 Youth]. Kukmin Ilbo, May 11, 1995.

Stryker, Susan. 2008. Transgender History. Berkeley: Seal Press.

Wang ŭi Namja [The King and the Clown]. 2005. Film. Directed by Kwŏn, Wŏn-ik. South Korea: Cineworld and Eagle Pictures.

Warner, Michael. 2002. Publics and Counterpublics. New York: Zone Books.

Yang, Sunyoung.

2017. "Networking South Korea: Internet, Nation, and New Subjects." Media, Culture \& Society 39(5): 740-749. http://journals.sagepub.com/doi/abs/10.1177/0163443717709443, accessed on July 1, 2018.

Yi, Kilho. 2012. Uri nŭn tissi: Tisi, Ingyŏ kŭrigo saibŏsŭp'eisŭ ŭi inryuhak [We are DC: DC, Surplus, and Anthropology of Cyberspace]. Seoul, South Korea: Imaejin.

Yi, Min-hŭi. 2013. P'aendŏm i kŏna ppasuni kŏna [Fandom or ppasuni]. P'aju, Gyeonggi-do: Alma.

Yi, Nuri. 2018. Sŏngp'ongnyŏk, woe p'ongno toel su pakke ŏpnŭnga [Sexual Harassment, Why Should It Be Exposed?] Seoul National University Journal 148, April 12. http://www.snujn.com/news/37534, accessed on July 1, 2018.

Yu, Min-sŏk. 2016. Megalia ŭi Panran [Megalian Revolt]. South Korea: Baume à l'âme.

Yun, Po-ra. 2017. "Megalia ŭi kŏŭl i pich'u nŭn myŏt kaji chilmun tŭl” [Several Questions Reflected in Megalia's Mirror]. In Kürŏm edo, P'eminisŭm [Nevertheless, Feminism], edited by Po-ra Yun et al., 9-28. Seoul: Ǔnhaengnamu. 